\title{
Cross-level effects of health-promoting leadership on nurse presenteeism: The mediation and moderation effect of workload and performance pressure
}

\author{
Geyan Shan ${ }^{1,2} \cdot$ Wei Wang ${ }^{1} \cdot$ Shengnan Wang ${ }^{1} \cdot$ Yongjun Zhang ${ }^{2} \cdot$ Yongxin $^{\mathrm{Li}^{1}}{ }^{\circledR}$
}

Accepted: 30 November 2021

(c) The Author(s) 2021

\begin{abstract}
This study examines the cross-level influence mechanism of leaders' health-promoting leadership on subordinates' presenteeism among nursing industry. A multilevel mediated moderation model was hypothesized to explore whether healthpromoting leadership is associated with subordinates' presenteeism via the workload of subordinates, and how leader's performance pressure plays the role in the model. Questionnaires were distributed to 110 nursing teams, which including 110 chief nurses and 660 subordinate nurses. Our findings showed that although health-promoting leadership has no direct impact on presenteeism, health-promoting leadership has an indirect impact on presenteeism via workload, and workload acts as a complete mediator. Meanwhile, performance pressure moderated the relationship between health-promoting leadership and workload. With an increase in performance pressure of leaders, the negative impact of health-promoting leadership on nurse workload gradually weakened. In this multilevel mediated moderation model, the mediated moderating effect of performance pressure was significant and the moderating effect was completely mediated, which means that the interaction between health-promoting leadership and performance pressure can affect presenteeism through workload. When leaders were under high performance pressure, the protective effect of health-promoting leadership on workload would be inhibited. These findings contribute to enriching the research on presenteeism, providing insight into how the health development of employees and performance demands of leaders may be balanced, and affording fresh thoughts for effective prevention and treatment of nurse presenteeism.
\end{abstract}

Keywords Presenteeism $\cdot$ Health-promoting leadership $\cdot$ Performance pressure $\cdot$ Workload $\cdot$ Multilevel model

\section{Introduction}

Yongxin $\mathrm{Li}$

liyongxin@henu.edu.cn

Geyan Shan

shan_geyan@163.com

Wei Wang

sea_wangwei@163.com

Shengnan Wang

nicolesnwang@163.com

Yongjun Zhang

Zhangyj0505@126.com

1 Institute of Psychology and Behavior, Henan University, Jinming Avenue, Kaifeng, Henan Province, China

2 Business School, Henan University, Jinming Avenue, Kaifeng, Henan Province, China
In recent years, presenteeism has become a common phenomenon in the workplace (Sun \& Zhang, 2015), which has been defined as the behavior of people who still turn up at their jobs despite complaints of ill-health (Aronsson et al., 2000). Existing literature indicated that presenteeism has a high incidence in the workplace, and the prevalence of presenteeism varied from $30 \%$ to more than $90 \%$ reported by fifteen countries or regions (Lohaus \& Habermann, 2019). Meanwhile, the negative influence of presenteeism has also been widely explored in multiple regards, such as the damage to employee health (Bergström et al., 2009), decreased job satisfaction (Zhang et al., 2018), and reduction of work productivity (Li et al., 2019; Shan et al., 2021b). Moreover, presenteeism was particularly prevalent among healthcare professionals (Aronsson et al., 2000; Gustafsson et al., 2020), and the unhealthy working behavior of them would 
bring a series of unfavorable consequences for themselves, patients, and organizations (Fiorini et al., 2020; Letvak et al., 2012).

Although the interest in presenteeism has been stimulated for scholars in different fields (e.g., Cooper \& Lu, 2016; Johns, 2010), considerable literature mainly focused on the occurrence and current situation of presenteeism (e.g., Ferreira \& Martinez, 2012; Navarro et al., 2018), or simply explored the occurrence mechanism of presenteeism from the perspective of individual perception (e.g., Deery et al., 2014; Furuichi et al., 2020). Considering that only few studies examined the influence of leaders on the presenteeism of subordinates from the perspective of interpersonal interaction in the workplace (e.g., Dietz et al., 2020), relevant studies need to be further enriched. Franke et al. (2014) indicated that researchers should pay more attention to the relationship between specific health-related behaviors and subordinate's health, because explaining the relationship between leaders and subordinates using leadership theory under specific circumstances would be more straightforward (Judge \& Kammeyer-Mueller, 2012). Therefore, the present study aimed to investigate the relationship between interpersonal factors and presenteeism from the perspective of healthy development.

Existing studies have shown that there exist close relationships between leader-related factors and employee presenteeism, such as perceived leader support (Miraglia $\&$ Johns, 2016) and leader-member exchange (Wang et al., 2018). Health-promoting leaders are the ones who directly influence employee's health or change the work environment (Jiménez et al., 2017a). They emphasize on creating a healthy working environment, promoting the healthy development of organizations, practicing health plans, formulating member development programs, and integrating external resources and the environment to promote the overall health of individuals (Barrett et al., 2005). Based on social learning (Bandura, 1977), leaders are more likely to be models for subordinates in the workplace because of power and a high position they possess. Hence, employees may imitate the behavioral patterns and attitudes of health-promoting leaders to make more health-promoting work decisions.

The present study hypothesized a cross-level mediated moderation model, which aimed to examine whether and how health-promoting leadership, as a resource-supported leadership, has impacts on subordinates' decision-making regarding unhealthy work behaviors. Work overload is a crucial stressor stemming from job demands (Gilboa et al., 2008). With the concern of health, health-promoting leaders might adjust subordinates' workload to minimize or avoid the occurrence of unhealthy work behavior of subordinates. However, leaders themselves would also come under performance-related pressure from their organizations, what was an important manifestation of their job demands.
High performance pressure forces leaders to make timely adjustments according to job demands and to balance the relationship the resources they could provide and the current job demands. In total, the present study focuses on the nursing industry where presenteeism occurs widely, takes the department as a unit to collect information of nurses and their direct leader, to investigate the cross-level effects of health-promoting leadership on nurse presenteeism and how the role that workload and performance pressure played in its relationship.

\section{Health-Promoting Leadership of Chief Nurses and Presenteeism of Nurses}

Presenteeism refers to the behavior of working in the state of ill-health (Ruhle et al., 2019), which is a widespread work behavior that is unfavorable for health recovery. Presenteeism is quite prevalent among Chinese nurses, and more than $90 \%$ of them have exhibited presenteeism in the past six months (Shan et al., 2021b). Furthermore, nurse presenteeism would not only impair their own health and wellbeing, but would also pose as a high risk to their patients and severe productivity losses to their organization (Freeling et al., 2020). Prior studies have suggested that nurse presenteeism has an adverse impact on patient safety, increases the incidence of patient falls and medication errors, and reduces the score of quality of care by patients (Letvak et al., 2012; Rainbow et al., 2020). In brief, presenteeism is not conducive to the treatment and rehabilitation of patients, which would further reduce the level and quality of nursing. Moreover, scholars have found that nurse presenteeism tends to reduce nurses' work engagement (Zhang et al., 2019a), increase their job burnout (Demerouti et al., 2009), and bring direct and indirect economic losses to their medical organizations (Letvak et al., 2012; Shan et al., 2021b). Therefore, scientifically preventing and managing nurse presenteeism has become a virtual issue to guarantee the quality of nursing.

Creating work conditions that support and enhance employee health could be an effective approach to reduce the unhealthy work behavior of employees. Jiménez et al. (2017b) pointed out that health-promoting leadership emphasizes on identifying the specific components of leadership behavior that have a positive influence on the working conditions of employees, the goal of which is to gradually design the working environment in a way that it is able to enhance health. Health-promoting leaders take responsibility for promoting employee health, improving working conditions that are beneficial to employee health, and demonstrate care for their health needs (Yao et al., 2021). Considering that any change in the state of team members will affect the state of the other members, the importance of leadership in subordinate behaviors is also noticeable. Employee health 
could be influenced by their leader's behavior in a variety of ways (Wegge et al., 2014), which is of great significance in shaping the healthy work behaviors of employees. In the workplace, subordinates are impacted by their leaders' attitudes, cognition, behavior, and relationships through the trickle-down effect; that is, the characteristics and behaviors of leaders can be transmitted through a top-down approach through a management hierarchy of vertical management, thus causing similar characteristics and behaviors among their subordinates and teams (Wang et al., 2015). Therefore, the chief nurse, as the direct leader of the nursing team, is an important mainstay in the team, and the behavioral style of chief nurses plays a crucial role in the organization. In addition, numerous studies have examined and verified the effect of leaders on subordinates by taking subordinates' responses as indicators of leadership effectiveness (Derue et al., 2011). It could be inferred that when the leader (chief nurse) has a high level of health-promoting leadership, team members (subordinate nurses) may exhibit less unhealthy work behavior (presenteeism) through top-down learning. In sum, the present study intends to examine the relationship between health-promoting leadership and presenteeism in the context of leader-subordinate interaction, and the following hypothesis was proposed.

\section{Hypothesis 1: There is a negative relationship between the health-promoting leadership of chief nurses and the presenteeism of subordinate nurses.}

\section{Mediation Effect of Nurses' Workload}

Role overload is a crucial stressor stemming from job demands that reflect stimuli that are perceived by individuals as placing demands upon them (Gilboa et al., 2008), which has a negative impact on individual work attitudes and teamwork (Wang \& Li, 2017), and would in turn be detrimental to the healthy development of employees. Existing research illustrates that heavy workload is one of the major reasons for employees' presenteeism (Biron et al., 2006; Deery et al., 2014). Workload is not a static concept that could be changed with a difference in job demands and employee's abilities (Veltman \& Gaillard, 1996), which demonstrates the subjective perception of the physiological and psychological costs that employees input to complete the task. It is one of the significant stressors related to work among individuals. When an individual's own resources are insufficient to cope with the external work requirements, the damaging pressure process is triggered; to cope with the pressure, the secondary factor, job resources, must be sacrificed (Bakker \& Demerouti, 2007; Demerouti et al., 2001). With regards to nurse presenteeism, when nurses experience poor health, if their heavy workload cannot be accomplished, they are likely to choose to work while sick, due to work pressure to ensure the smooth fulfillment of their job requirements. Hence, workload may contribute to the occurrence of presenteeism.

Health-promoting leadership is a resource-supporting leadership style. Health-promoting leaders would adopt different health management strategies or employee healthpromoting projects according to different organizational situations and atmospheres. The awareness of promoting employees' health that leaders demonstrate, enables them to set appropriate work pressure for subordinates, adopt democratic management methods, and provide supportive services and guaranteed resources, thereby helping employees fulfill job demands and alleviate the pressure of work (Gregersen et al., 2014; Liu, 2016). Anita et al. (2015) expounded, from the perspective of reducing job exhaustion, that an important aspect of health-promoting leadership is to control the workload of organizations and individuals at a competent level by providing sufficient resources. Therefore, chief nurses with high health-promoting leadership might supply more available coping resources for the subordinate nurses to effectively reduce their perceived workload. In conclusion, we speculate that the health-promoting leadership of chief nurses could reduce the workload of their subordinates, thus decreasing the occurrence of presenteeism among nurses in poor health, and the following hypothesis was proposed:

Hypothesis 2: Nurses' workload is a mediator in the relationship between chief nurses' health-promoting leadership and presenteeism among nurses.

\section{Moderation Effect of Chief Nurses' Performance Pressure}

The effectiveness of leadership depends on the coordination between the leader, followers, and situational conditions, which are significantly impacted by the situational factors related to leader behaviors (Liu, 2008). Thus, when considering the impact of leadership behavior on subordinates' workload, attention should also be paid to the effect of organizational situation factors on the relationship between health-promoting leadership and workload.

Performance pressure denotes the subjective experience wherein individuals have to enhance their performance to avoid adverse consequences (Mitchell et al., 2018). In a nutshell, it is the pressure that individuals perceive regarding performance. In terms of leaders' situations, leaders would also be affected by the organization-related pressure while arranging and coordinating the work of subordinates. High performance pressure tends to signify high risk and heavy demand, suggesting that the current performance is insufficient and that the level of performance needs to be improved through various means ( $\mathrm{Li}$ et al., 2018). Under heavy job demands, people need to utilize a vast amount of existing job resources to accomplish their 
job objectives (Bakker \& Demerouti, 2007). Turgut et al. (2020) indicated that managers can reasonably expect to set other priorities under work pressure. Therefore, when leaders are under high performance pressure, competition is formed between the current high job demands and the resources that leaders can provide to subordinates. To achieve performance goals, leaders need to improve their own and subordinates' job demands. However, from the perspective of health-promoting leadership, to promote the sustainable development of organizations and employees, leaders adjust employees' workload by providing enough resources to maintain it at a reasonable level (Anita et al., 2015). Consequently, when leaders are under high performance pressure, they may reduce the resources used to regulate the workload of subordinates to deal with the high risks and threats they face. In other words, health-promoting leaders who are under high performance pressure face a dilemma between organizational performance and health promotion: raising demands or providing resources. Based on the above analysis, we supposed that the high performance pressure leaders face might weaken the negative effect of health-promoting leadership on subordinates' workload, and the following hypothesis was put forward.

Hypothesis 3: Leaders' performance pressure moderates the relationship between chief nurses' health-promoting leadership and workload among nurses, such that the relationship is weaker when leaders' performance pressure is higher.

As outlined, the present study concerns the impact of leaders on subordinates, which was expected to help explore the cross-level influence of health-promoting leadership on subordinates' presenteeism through the sampling method of team-matching. Simultaneously, the performance pressure of the leader was included as a moderating variable and the subordinates' workload was incorporated as the mediating variable, to further examine the crosslevel influence mechanism of health-promoting leadership on subordinates' unhealthy work behavior. The integrated conceptual model is shown in Fig. 1.

\section{Method}

\section{Participants and Procedure}

In the current study, paired data were collected through a paper survey that considered the department as a group. Four 3A-grade hospitals located in Henan province of China participated in this investigation, and one chief nurse and six subordinate nurses from every department in those hospitals were selected through convenience sampling. A total of 110 sets of questionnaires were distributed to the 110 departments in those four hospitals. Each set of questionnaires consists of seven questionnaires, in which, one questionnaire was required to be filled out by the chief nurse and six questionnaires were filled out by their subordinate nurses. Participants were informed that they should complete the questionnaire independently, and that the content of the questionnaire was entirely confidential. Subsequently, 98 sets of effective questionnaires were recycled, which included 98 chief nurses' questionnaires and 528 subordinate nurses' questionnaires. The effective response rate of the department (chief nurse) was $89.09 \%$, and the effective response rate of subordinate nurses was $80.00 \%$. For chief nurses, 95 (95.92\%) were female, the average age was 40.21 years $(\mathrm{SD}=5.94)$, and their average tenure in nursing was 20.09 years $(\mathrm{SD}=7.18)$. Meanwhile, $94(95.92 \%)$ of the chief nurses were married, 68 (69.39\%) had the title of nurse-in-charge, and 28 (28.57\%) had the title of associate professor of nursing or professor of nursing. For subordinate nurses, $516(97.73 \%)$ were female, their average age was 30.16 years $(\mathrm{SD}=4.83)$, their average tenure in nursing was 8.31 years $(\mathrm{SD}=5.23)$, and $316(59.85 \%)$ of the nurses were married. Regarding the technical title, $86(16.29 \%)$ had the title of nurse, $196(37.12 \%)$ had the title of nurse practitioner, and $230(43.56 \%)$ had the title of nurse-in-charge or above. The department where participants worked covers internal medicine, surgery, pediatrics, obstetrics and gynecology, emergency, among others.

Prior to the survey conducted, the questionnaire was coded and distributed by researchers which comprised four psychology graduate students and four nursing students with undergraduate degrees and training. After identifying the

Fig. 1 Hypothesized conceptual model

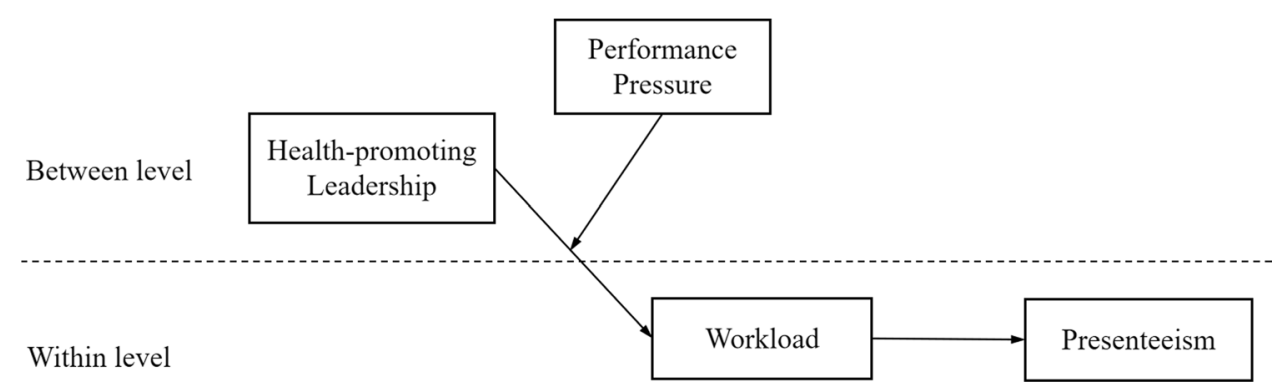


nurses' non-working hours and obtaining the oral permission of the nursing director, researchers entered the hospital and distributed questionnaires. It was then returned to the researchers after being filled out. To ensure the authenticity of the questionnaires, we kept the purpose of questionnaires confidential, and the contents of the questionnaires were filled by nurses and chief nurses independently. All participants provided oral informed consent prior to completing the questionnaire. This survey was approved by the research ethics committee of the authors' academic institution.

\section{Measures}

\section{General Demographic Variables}

General demographic characteristics such as gender, age, tenure, marital status, technology title, and department were collected. Among them, age and tenure were directly filled in the questionnaire, and other information was collected in the form of multiple choices.

\section{Nurse Presenteeism}

The nurse presenteeism questionnaire developed by Shan et al. (2021a) was used to assess the occurrence of presenteeism among nurses in the past six months, which consists of 11 items. An example item is "although you felt dizzy or had a headache, you still persevered in going to work." Participants were required to rate how often they had exhibited presenteeism during the past six months, and each item was rated on a four-point scale $(0=$ never, $1=$ once, $2=2-5$ times, $3=$ more than 5 times), with high scores representing more frequent instances of presenteeism. During instruction, participants were informed not to repeat reports (select 0 ) if the following situations occurred as part of the same round of sick attendance behavior. Meanwhile, the questionnaire defined the severity of the disease in each presenteeism as follows: although behavioral competence is basically normal, having a significant sense of discomfort, and which can be overcome or mitigated with a certain amount of willingness and effort. In this study, the internal reliability consistency coefficient was 0.94 .

\section{Health-Promoting Leadership}

The health-promoting leadership conditions were adopted to measure the health-promoting leadership of chief nurses, which includes seven dimensions: health awareness, workload, control, reward, community, fairness, and value-fit (Jiménez et al., 2017a). Each dimension has three items that make 21 items in total, and all items were assessed on a seven-point Likert scale ranging from 0 (never) to 6 (always). Before applying the scale, it was translated into
Chinese and made slight modifications to adapt the tool to the Chinese culture and context. Then, a native-English speaker researcher who was unfamiliar with the scale backtranslated the scale into English and compared it with the primary questionnaire to ensure that the meanings of the sentences were the same. In the present study, the healthpromoting leadership of chief nurses was evaluated by their subordinate nurses, and the average score of nurses in the same team was taken as their leader's score. The overall internal consistency coefficient of this scale was 0.98 , and the internal consistency coefficient of the seven dimensions in the scale ranged from 0.91 to 0.98 .

\section{Performance Pressure}

Four items from the performance pressure scale, which was developed by Mitchell et al. (2018), were adopted to evaluate the performance pressure faced by chief nurses. A sample item is "If I do not produce at high levels, my job will be at risk". All items were scored on a five-point Likert scale ranging from 1 (strongly disagree) to 5 (strongly agree). The scale has been widely adopted by Chinese scholars, which has good reliability and validity ( $\mathrm{Li}$ et al., 2018). In the present study, the internal consistency coefficient for this scale was 0.70 .

\section{Workload}

The role overload scale developed by Peterson et al. (1995) was used to evaluate the workload of nurses, which contains five items rated on a five-point Likert scale ranging from 1 (strongly disagree) to 5 (strongly agree). A sample item is "It will be necessary to reduce some of my work duties". The scale has been widely adopted by Chinese scholars to measure workload, and has good reliability and validity (Wang $\& \mathrm{Li}, 2017)$. In the present study, the internal consistency coefficient for this scale was 0.92 .

\section{Data Analysis}

We tested our hypotheses using the Mplus statistical package version 7.4 (Muthén \& Muthén, 2017) and the statistical software HAD (Shimizu, 2016) for data sorting and analysis. Combined with the content of the present study, data processing was mainly conducted in the following three steps. First, descriptive statistics were used to analyze the demographic variables and research variables. Second, we evaluated the applicability of the data, such as the withingroup agreement $(\mathrm{Rwg})$ and intraclass correlation coefficient (ICC) of between-group variables. The correlation among these variables was assessed using multi-level correlation analysis. Finally, to verify the hypotheses of this study, a cross-level mediated moderating model was constructed to 
test the whole hypothesized conceptual model, and a crosslevel mediation-lower mediation model and a cross-level moderation model were built to further examine whether each hypothesis was valid.

\section{Results}

\section{Applicability of Research Data}

A null model test was conducted for mediator and dependent variables at the within-team level, and it was assumed that workload and presenteeism were affected at both the within and between levels, thus having inter-group variance and between-group variance, respectively. Mplus software was used to calculate the intraclass correlation coefficient (ICC) of workload and presenteeism. The results showed that the ICC(1) of workload was 0.27 and the ICC(1) of nurse presenteeism was 0.28. According to James (1982), betweengroup variance should be considered when the inter-group correlation is higher than 0.12 . Therefore, the multilevel analysis method was suitable for the present study.

In the present study, the health-promoting leadership of chief nurses was rated by their subordinate nurses, so it was necessary to evaluate the within-team consistency before aggregating it to the between-team level. The results showed that the mean within-group agreement Rwg (j) of the healthpromoting leadership was 0.79 , ICC(1) was 0.40 , and ICC(2) was 0.71 . According to the suggestions of Chen and Shen (2014), if $\operatorname{Rwg}(j)>0.7, \operatorname{ICC}(1)>0.12$, and $\operatorname{ICC}(2)>0.5$, there is a significant difference in the between-group variance, and these variables can be aggregated. Therefore, health-promoting leadership was aggregated into a betweenlevel variable in the data analysis process.

\section{Descriptions and Correlations}

For convenience, HAD software (Shimizu, 2016) was used for descriptive statistical and multilevel statistical correlation analysis. The details are presented in Table 1. The results showed a significant positive correlation between nurse workload and nurse presenteeism at the between-team level $(r=0.36, p<0.01)$. At the within-team level, there was a negative correlation between leader health-promoting leadership and nurse workload $(r=-0.39, p<0.05)$, and between leader performance pressure and leader health-promoting leadership ( $r=-0.21, p<0.05)$. Meanwhile, there was a positive correlation between nurses' workload and nurse presenteeism $(r=0.74, p<0.01)$.

\section{Model Testing}

In the present study, we constructed a two-level mediated moderating model to test the hypotheses. First, nursing tenure and the level of technology among subordinate nurses were added to the model as control variables because of the significant correlation between these variables and nurse presenteeism. The results showed a good fit for this model $\left(\chi^{2} / d f=3.17, p<0.05, \mathrm{CFI}=0.96, \mathrm{RMSEA}=0.065\right)$, but the path coefficients of the above control variables were not significant $(p>0.05)$. To simplify the model, the control variables were removed in the present study, and the path coefficients barely changed in this model. Furthermore, the statistical power would decline by an excess of control variables (Becker, 2005), thereby the results of the simplified model would be reported in the present study. Considering that the simplified model displayed a saturated model, that is, the parameters to be estimated were exactly equal to the elements in the covariance matrix, and the degree of freedom was 0 , its fit index was not estimated, and its

Table 1 Descriptive statistics and correlations among study variables

\begin{tabular}{|c|c|c|c|c|c|c|c|c|c|c|}
\hline & $M \pm S D$ & 1 & 2 & 3 & 4 & 5 & 6 & 7 & 8 & 9 \\
\hline 1. Age & $30.16 \pm 4.83$ & & $0.90^{* *}$ & 0.09 & $0.61 * *$ & $0.67 * *$ & & & 0.09 & 0.08 \\
\hline 2. Tenure & $8.31 \pm 5.23$ & $0.98 * *$ & & 0.07 & $0.55^{* *}$ & $0.59 * *$ & & & $0.10^{*}$ & $0.12 *$ \\
\hline 3. Gender & $1.98 \pm 0.15$ & $0.18 *$ & 0.21 & & 0.02 & 0.08 & & & -0.02 & 0.04 \\
\hline 4. Marital status & $1.64 \pm 0.48$ & $0.80 * *$ & $0.76^{*}$ & 0.26 & & $0.56^{* *}$ & & & 0.05 & 0.06 \\
\hline 5. Technical level & $3.24 \pm 0.80$ & $0.93 *$ & $0.94 * *$ & 0.32 & 0.73 & & & & 0.05 & $0.10^{*}$ \\
\hline 6. Health-promoting leadership & $4.86 \pm 1.10$ & -0.85 & -0.01 & -0.03 & -0.03 & 0.09 & & & & \\
\hline 7. Leader performance stress & $2.64 \pm 0.72$ & 0.04 & -0.04 & 0.01 & 0.20 & 0.19 & $-0.21 *$ & & & \\
\hline 8. Nurse workload & $2.86 \pm 0.86$ & 0.39 & 0.24 & -0.02 & $0.52 *$ & 0.31 & $-0.39 * *$ & -0.01 & & $0.36 * *$ \\
\hline 9. Nurse presenteeism & $2.42 \pm 0.85$ & $0.42 *$ & 0.25 & 0.08 & 0.41 & 0.46 & -0.21 & 0.01 & $0.74 * *$ & \\
\hline
\end{tabular}

$N=528$ nurses nested in 98 teams; correlations on the within-level $(N=528)$ below the diagonal and on the between-level $(N=98$ teams $)$ above the diagonal; Age and tenure were continuous variables; Gender: $1=$ male, $2=$ female; Marital status: $1=$ unmarried, $2=$ married; Technical level: $1=$ student nurse, 2 = general nurse, $3=$ senior nurse, 4 = professor of nursing or above; $* p<.05, * * p<.01$ 
path coefficient was only considered (Zhang et al., 2019b). The results of the multilevel path analysis are presented in Table 2.

The results of the two-level mediated moderating model showed that the direct effect of health-promoting leadership on presenteeism was not significant $(\gamma=0.06, p=0.40,95 \%$ $\mathrm{CI}=[-0.081,0.205])$, and Hypothesis 1 was not supported. At the between-team level, health-promoting leadership had a significant negative impact on subordinate workload $(\gamma=-0.24, p<0.01,95 \% \mathrm{CI}=[-0.393,-0.087])$, and workload positively predicted presenteeism among nurses, suggesting a mediating effect of workload on the relationship between health-promoting leadership and presenteeism. Thus, Hypothesis 2 was supported. Moreover, the interaction between health-promoting leadership and performance pressure had a significant positive impact on subordinate workload $(\gamma=0.18, p<0.05,95 \% \mathrm{CI}=[0.018,0.345])$, which illustrated that performance pressure moderated the relationship between health-promoting leadership and workload. Thus, Hypothesis 3 was supported. According to the judgment method of Liu et al. (2012), the practical mediated moderating effect value of performance pressure was equal to the product of the coefficient of path $a$ and path $b$ (b1 and b2). Consequently, the mediated moderating effect of performance pressure was significant $(\gamma=0.14, p<0.05$, $95 \% \mathrm{CI}=[0.007,0.280])$. Given that the interaction between health-promoting leadership and performance pressure had no significant impact on presenteeism $(\gamma=-0.05, p=0.56$, $95 \% \mathrm{CI}=[-0.213,0.076])$, the moderating effect was completely mediated. Figure 2 depicts the global structural model and the unstandardized coefficients of each path.

A diagram of the moderating effect was drawn to intuitively present the role of performance pressure in the relationship between health-promoting leadership and workload (see Fig. 3). The results demonstrated that health-promoting leadership had no significant influence on nurse workload at a high level of performance pressure $(\gamma=-0.11, p=0.19)$, but there was a negative influence of health-promoting leadership on nurse workload at a low level of performance pressure $(\gamma=-0.37, p<0.01)$. With the increase in performance pressure among leaders, the negative impact of health-promoting leadership on nurse workload gradually weakened.

Furthermore, we examined the mediating effect of workload between health-promoting leadership and presenteeism at the within-team and between-team levels, respectively. According to the method of Fang et al. (2010), a cross-level mediation-lower mediator model (2-2-1 model) was conducted to test the cross-level mediation of workload using
Table 2 Results of multilevel path analysis

Fig. 2 Result of multi-level structural equation model. Note: Dashed line equal non-significant paths

\begin{tabular}{lll}
\hline Paths & $\gamma$ & $S E$ \\
\hline Within level & & \\
$\quad$ Workload $\rightarrow$ Presenteeism & $0.36^{* *}$ & 0.06 \\
Between level & & \\
$\quad$ Health-promoting leadership $\rightarrow$ Workload & $-0.24^{* *}$ & 0.08 \\
Performance pressure $\rightarrow$ Workload & -0.04 & 0.07 \\
Health-promoting leadership $\times$ Performance pressure $\rightarrow$ Workload $(a)$ & $0.18^{*}$ & 0.08 \\
Workload $\rightarrow$ Presenteeism $(b b)$ & $0.79^{* *}$ & 0.11 \\
Health-promoting leadership $\rightarrow$ Presenteeism & 0.06 & 0.07 \\
Performance stress $\rightarrow$ Presenteeism & 0.01 & 0.06 \\
Health-promoting leadership $\times$ Performance pressure $\rightarrow$ Presenteeism & -0.07 & 0.07 \\
Effect $(a * b b)$ & $0.14^{*}$ & 0.07 \\
\hline
\end{tabular}




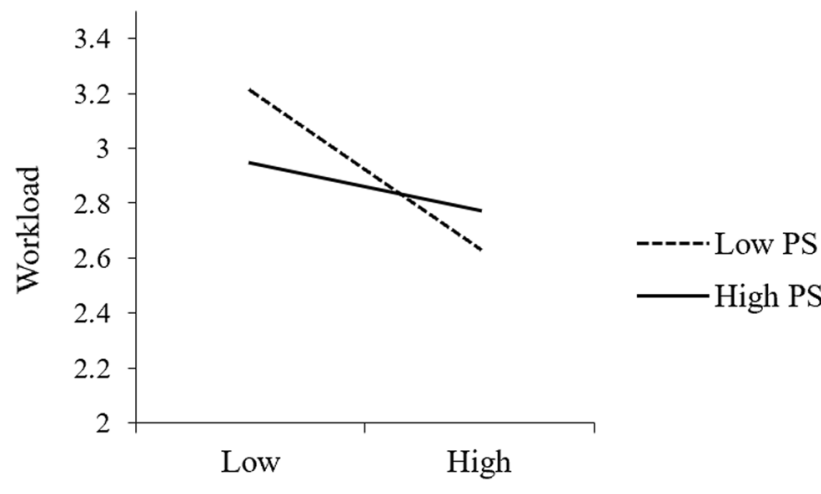

Health-ptomoting leadership

Fig. 3 Moderation effect of performance stress between health-promoting leadership and workload

the product of the coefficient. The model diagram is shown in Fig. 4, and the multilevel path analysis results of the mediation effect are displayed in Table 3.

As shown in Table 3, workload was a significant mediator between health-promoting leadership and presenteeism both at the within-team and between-team levels $\left(\gamma_{w}=-0.08\right.$, $p<0.01,95 \% \mathrm{CI}=[-0.141,-0.021] ; \gamma_{b}=-0.17$, $p<0.01,95 \% \mathrm{CI}=[-0.293,-0.045])$. Likewise, the total mediating effect was significant $(\gamma=-0.25, p<0.01$, $95 \% \mathrm{CI}=[-0.424,-0.076])$. Hypothesis 2 was further supported. In addition, because the indistinctive effect of healthpromoting leadership on nurse presenteeism behavior was $(\gamma=0.05, \mathrm{P}=0.48,95 \% \mathrm{CI}=[-0.089,0.187])$, workload was a complete mediator in the relationship between the two variables.

\section{Discussion}

Health is the basis of human survival and the significant resource for national development. Employee health is an important capital element for any organization. Healthy working conditions and healthy working behaviors of employees are essential elements in the creation of a healthy workplace (Hewison \& Griffiths, 2004). Nurses are one of the most critical players in universal healthcare (Crisp et al., 2018), and are the largest group in the Chinese medical service workforce. Naturally, they undertake an important task in the healthy development of nationals. However, nurses have a high incidence of presenteeism, and this behavior tends to result in serious adverse consequences for individuals, service objects, and medical organizations (Shan et al., 2021b). Therefore, our study focused on the occurrence mechanism of presenteeism among the nursing industry, from the perspective of health promoting. In addition, leaders have a momentous impact on their subordinates, which is one of the most important relationships that affect individuals' happiness in the workplace (Kelloway \& Barling, 2010). In the nursing industry, chief nurse acts both as the direct leader of the general and voice for professional nurses (Ingwell-Spolan, 2016), they work together with subordinates

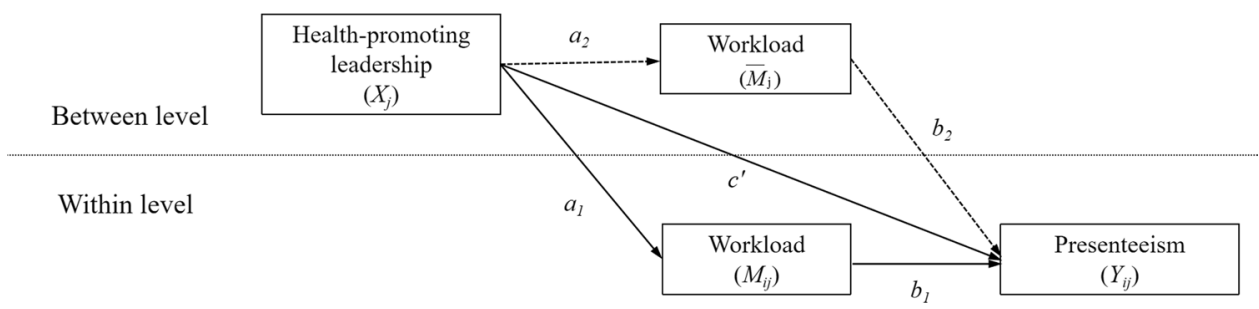

Fig. 4 Mediation effect of workload between health-promoting leadership and presenteeism. Note: Design of the 2-2-1 Model with cross and unique cluster-level mediation in solid and dotted lines, respectively. $X_{j}$ represents health-promoting leadership for a given team $\mathrm{j}$,
$M_{i j}$ and $Y_{\mathrm{ij}}$ represent staff nurses' workload and presenteeism, respectively, for employee $i$ in cluster $j, \bar{M}_{j}$ represents the team aggregate nurse workload. The $a_{1}$ - and $a_{2}$-path are assumed to be equal in this model
Table 3 Multilevel path analysis of the mediation effect

\begin{tabular}{llll}
\hline & & $\gamma$ & $S E$ \\
\hline Path $a$ & Health-promoting leadership $\rightarrow$ Workload & $-0.22^{* *}$ & 0.07 \\
Path $b_{1}$ & Workload $\rightarrow$ Presenteeism & $0.76^{* *}$ & 0.11 \\
Path $b_{2}$ & Workload $\rightarrow$ Presenteeism & $0.36^{* *}$ & 0.06 \\
Direct effect $\left(c^{\prime}\right)$ & Health-promoting leadership $\rightarrow$ Presenteeism & 0.05 & 0.07 \\
Within-indirect effect & Health-promoting leadership $\rightarrow$ Workload $\rightarrow$ Presenteeism & $-0.08^{* *}$ & 0.03 \\
Between-indirect effect & Health-promoting leadership $\rightarrow$ Workload $\rightarrow$ Presenteeism & $-0.17^{* *}$ & 0.06 \\
Total effect & Health-promoting leadership $\rightarrow$ Presenteeism & $-0.20^{*}$ & 0.10 \\
\hline
\end{tabular}


at the front line, shoulder the responsibility of supervising and managing the work of nurses, and play dual roles of collaborators and leaders. Considering the close connection between chief nurses and nurses, the present study examined the influence mechanism of leaders' health-promoting leadership on subordinate presenteeism in nursing workplaces through a cross-level research design.

The present study indicated that the negative relationship between chief nurses' health-promoting leadership and nurses' presenteeism was not significant. The reason may be that presenteeism is a consequence of an individual's complex decision-making process. Complicated interactional mechanisms exist in the relationship between healthpromoting leadership and presenteeism, so it is difficult to make a simple judgment on its direct effect. In the view of the connotation of health-promoting leadership (Skarholt et al., 2016), health-promoting leaders have the consciousness of health promotion, attach importance to the healthy environment and development in the workplace. Since health-promoting leadership is designed to promote healthy work and healthy development, it may be closely related to presenteeism of employees. However, we additionally found that disparate hypothetical results emerged when we tried to explain the causes of presenteeism from different theoretical perspectives. For instance, from the perspective of the social learning theory (Bandura, 1977), the leader, as the figurehead of high power and rich resources, represents their organization, whose concepts and attitudes of health are likely to be learned by subordinates, plays an important role in contributing to decreasing subordinates' presenteeism. Conversely, from the social exchange theory (Blau, 1964), when a subordinate experienced a supportive resource from leaders, they would reward themselves' resources to their leaders, i.e., reciprocating leaders by doing something beneficial to them, to maintain the benefit exchange relationship, Hence, they might persevere in their work despite feeling sick, in order to avoid increasing additional tasks for their team and workmates. It also revealed the necessity of conducting richer and deeper research on the causes of presenteeism, which is conducive to further clarifying the main clues behind the complex decision-making that goes into presenteeism, and constructing an integrated theoretical framework of presenteeism.

The results of this study showed that workload played a mediating role in the relationship between health-promoting leadership and nurse presenteeism, both at the between level and the within level. Health-promoting leaders could indirectly reduce nurse presenteeism through decreasing the perceived workload of individual subordinates and the whole team. Heavy workload, as a stressor based on job requirements (Gilboa et al., 2008), often brings negative effects on individual work attitude and team cooperation (Wang \& Li, 2017), which is not conducive to the healthy development of employees. Previous studies have pointed out that the high level of job requirements is an important antecedent for the occurrence of presenteeism (Deery et al., 2014; Demerouti et al., 2009; Gillet et al., 2020). The chief nurses' health-promoting leadership could be seen as work resources of subordinates in the nursing workplace, which provide supports to nurses for coping with the high level of job demands. It is helpful to reduce the heavy job requirement experienced by nurses, and further conducive to decrease the risk of presenteeism of team members under high job demands. In other words, the impact of health-promoting leadership on nurse presenteeism reflects on the reasonable adjustment of subordinates' workload, which provides subordinates with more resources to cope with job requirements through setting a rational workload, thus reducing the behavior of subordinates that sacrifice individual health to fulfill job requirements.

The present study further showed that performance pressure faced by leaders could moderated the effect of healthpromoting leadership on subordinates' workload. Specifically, when leaders were under low level of performance pressure, health-promoting leadership had a negative effect on nurses' workload, but the effect does not exist when leaders were under high level of performance prestress. In order to promote the sustainability of organizations and employees, health-promoting leaders would manage subordinates' workloads at reasonable levels through providing sufficient resources to them (Anita et al., 2015). However, the high level of performance pressure means the high level of job requirement, pressurizing leaders to improve the insufficient performance through various means ( $\mathrm{Li}$ et al., 2018). Under high job requirements, individual need to mobilize existing resource to achieve the goal of tasks (Bakker \& Demerouti, 2007). In this case, the competition would be form between the resources that leaders could provide to subordinates and the current high job requirements that leaders confront. Meanwhile, when leaders were under high pressure, the prioritization of important matters might be reset by them (Turgut et al., 2020). They needed to weigh the choice between promoting employees' health and achieving performance requirements, then reallocate resources and select current priorities. Therefore, high performance pressure of leaders weakened the negative effect of health-promotion leadership on subordinates' workload.

Overall, we found support for the proposed model. Although health-promoting leadership did not have a direct influence on nurse presenteeism, it could indirectly reduce the occurrence of presenteeism by decreasing the perception of employees' workload. However, the negative impact of health-promoting leadership on subordinates' workload was weakened when leaders had high performance pressure. Generally, the interaction between health-promoting leadership and leader performance pressure had a significant 
impact on nurse workload, which further influenced nurse presenteeism. Therefore, health-promoting leadership is an effective protective factor to decrease nurse presenteeism, which plays an indirect role through nurse workload, but its protective effect on nurse presenteeism is moderated by their own performance pressure.

\section{Theoretical Implications}

This research explored the mechanism of nurse presenteeism from the perspective of interpersonal interaction, which investigated leader-related factors of nurse presenteeism and further explained the mechanism behind the occurrence of unhealthy work behavior. Since only few studies have emphasized on the cross-level influence of leader-related factors on the presenteeism of subordinates, the present study explored the effects of health-related leadership on presenteeism at both the team and individual levels. Meanwhile, the present study also elaborated on the protective effects of health-promoting leadership on employee work behavior, which preliminarily responded to the suggestions of Yao et al. (2021). These findings supported the significant role that leader played for decision-making of presenteeism, and provide multidimensional directions for balancing the interests of the organization and employees.

Prior studies have shown that health-promoting leadership provides employees with adequate work resources and sufficient job autonomy (Bregenzer et al., 2019), and the results of the present study provide further evidence towards the literature on health-promoting leadership. The findings supported the hypothesis stating that health-promoting leadership fosters followers' health and well-being (Jiménez et al., 2017b), and supplemented the consequence research of health-promoting leadership, which contributes to reducing the negative work behavior of nurses. From the theoretical connotation of health-promoting leadership, health-promoting leaders work to create a culture that fosters health-promoting workplaces and values, and to inspire and motivate employee participation in such developmental activities (Skarholt et al., 2016). Health-promoting leadership is designed to promote healthy work habits and the healthy development of employees; thus, it may reduce unhealthy work behaviors. Future research needs to discuss the effects of health-promoting leadership from a more comprehensive perspective, which includes positive-promoted behavior and negative-decreased behavior within the same framework.

\section{Practical Implications}

First, the present study tentatively explored how work resources play a vital role in the adaptation process of individual health and performance needs (Karanika-Murray \&
Biron, 2020). The findings indicated the importance of work resources for nurses' health work behavior and revealed the trickle-down influence mechanism of health-related leadership on subordinates' work behavior. To some extent, the present study provides inspiration for leaders on how to make decisions regarding personal health and performance needs, and supplies more scientific and effective management to help prevent and reduce the occurrence of nurse presenteeism.

Second, the results of the present study pointed out the significant influence of job demand-related factors, such as workload of nurses and performance pressure of chief nurses, on the occurrence of nurse presenteeism. Therefore, for the prevention and management of nurse presenteeism, it is important to be concerned about nurses' health and appropriately reduce their workload (Lee et al., 2020). More importantly, management departments should place emphasis on the interaction process between the behavior of leaders and subordinates, as well as reasonably program and regulate the work content and pressure among nursing managers and frontline nurses. The establishment of a standardized health development and management system may be helpful in improving awareness on health promotion. Meanwhile, providing scientific training in health promotion management could contribute to creating a healthy working atmosphere.

Third, the present study responds to the call for "Healthy China" as nurses shoulder the essential responsibility of national health education and development. In contrast, with an occupational population with high health literacy, nurses showed a high level of unhealthy work behaviors (Shan et al., 2021b). Thus, conducting research on nurse presenteeism would facilitate bringing widespread attention to the occupational health of nurses. Furthermore, the increased attention and research in the nursing industry could boost the enhancement of the level and quality of nursing, and contribute to the smooth progress of the program of "Healthy China 2030".

\section{Limitations and Future Directions}

Although the present study enriches the relevant research on presenteeism and health-promoting leadership in a sample of Chinese nurses, it is important to consider these findings in light of potential limitations. First, although the present study collected data from two sources - nurses and chief nurses, which is helpful in reducing the risk of common method variance and exploring the role of interpersonal interaction in the workplace, a cross-sectional study design was used in this research. Thus, the findings may be limited in explaining the causal relationships. In future research, a longitudinal study design should be conducted to test the robustness of the results. Second, the sample proportion of 
female participants was high in the present study. Although the proportion of samples is consistent with the gender ratio in the nursing industry of China (Zhou et al., 2021), researchers must be more cautious with the generalization of these results for regions with different cultural backgrounds. Future research should also investigate the crosscultural consistency of presenteeism. Finally, although our study investigates the leader's direct influence in the workplace on subordinates' presenteeism, contextual factors at the organizational level have not been sufficiently included in the model. Hence, the theoretical model or system of the occurrence of presenteeism is difficult to form, and the relationship between health-promoting leadership and employee presenteeism is not sufficient for in-depth interpretation from the perspective of organizational ecology. Future research should integrate more stakeholder-related factors with organizational variables in nursing workplaces, to gain a more comprehensive and dynamic understanding of the mechanism of nurse presenteeism, and then provide a basis for the development of effective nursing management programs.

\section{Conclusion}

For healthcare service workers, unhealthy work behaviors cause serious adverse effects on themselves, patients, and their organizations. The present study revealed the relationship between the health-promoting leadership of chief nurses and presenteeism among nurses from the perspective of interpersonal interaction. The results demonstrated that health-promoting leadership is conducive to reducing the workload of nurses, and then further decreases the occurrence of presenteeism. The performance pressure of chief nurses moderates the negative relationship between healthpromoting leadership and nurses' workload, and there is a choice to promote health or achieve performance on the part of leaders. Our findings proved that supportive leadership has the advantage of decreasing the incidence of presenteeism among nurses. It would be conducive to reduce unhealthy work behaviors that appropriately decrease the performance pressure of chief nurses, reduce the workload of subordinate nurses, and construct a scientific and reasonable work distribution system, which would further promote the improvement of nurse occupational health.

Author Contributions All authors listed have made a substantial, direct and intellectual contribution to the work. Material preparation, data collection and analysis were performed by Geyan Shan, Wei Wang, Shengnan Wang, Yongjun Zhang and Yongxin Li. The first draft of the manuscript was written by Geyan Shan and all authors commented on previous versions of the manuscript. All authors read and approved the final manuscript.
Funding This research supported by the National Natural Science Foundation of China (Grant No. 72101083).

Data Availability The datasets generated for this study are available on request to the corresponding author.

\section{Declarations}

Ethics Approval The studies involving human participants were reviewed and approved by the Research Ethics Committee of the Institute of Psychology and Behavior, Henan University. Written informed consent to participate in this study was provided by the participants.

Conflicts of Interest The authors declare that the research was conducted in the absence of any commercial or financial relationships that could be construed as a potential conflict of interest.

Open Access This article is licensed under a Creative Commons Attribution 4.0 International License, which permits use, sharing, adaptation, distribution and reproduction in any medium or format, as long as you give appropriate credit to the original author(s) and the source, provide a link to the Creative Commons licence, and indicate if changes were made. The images or other third party material in this article are included in the article's Creative Commons licence, unless indicated otherwise in a credit line to the material. If material is not included in the article's Creative Commons licence and your intended use is not permitted by statutory regulation or exceeds the permitted use, you will need to obtain permission directly from the copyright holder. To view a copy of this licence, visit http://creativecommons.org/licenses/by/4.0/.

\section{References}

Anita, D., Paul, J., Simona Šarotar, Ž, Borut, M., \& Wolfgang, K. K. (2015). Similarities and differences of health-promoting leadership and transformational leadership. Naše Gospodarstvo/our Economy, 61(4), 3-13. https://doi.org/10.1515/ngoe-2015-0013

Aronsson, G., Gustafsson, K., \& Dallner, M. (2000). Sick but yet at work. An empirical study of sickness presenteeism. Journal of Epidemiology and Community Health, 54(7), 502-509. https:// doi.org/10.1136/jech.54.7.502

Bakker, A., \& Demerouti, E. (2007). The job demands-resources model: State of the art. Journal of Managerial Psychology, 22, 309-328. https://doi.org/10.1108/02683940710733115

Bandura, A. (1977). Social learning theory. Prentice-Hall.

Barrett, L., Plotnikoff, R. C., Raine, K., \& Anderson, D. (2005). Development of measures of organizational leadership for health promotion. Health Education and Behavior, 32(2), 195-207. https:// doi.org/10.1177/1090198104271970

Becker, T. E. (2005). Potential problems in the statistical control of variables in organizational research: A qualitative analysis with recommendations. Organizational Research Methods, 8(3), 274 289. https://doi.org/10.1177/1094428105278021

Bergström, G., Bodin, L., Hagberg, J., Aronsson, G., \& Josephson, M. (2009). Sickness presenteeism today, sickness absenteeism tomorrow? A prospective study on sickness presenteeism and future sickness absenteeism. Journal of Occupational and Environmental Medicine, 51(6), 629-638. https://doi.org/10.1097/JOM.0b913 e3181a8281b

Biron, C., Brun, J. P., Ivers, H., \& Cooper, C. (2006). At work but ill: Psychosocial work environment and well-being determinants of 
presenteeism propensity. Journal of Public Mental Health, 5(4), 26-37. https://doi.org/10.1108/17465729200600029

Blau, P. M. (1964). Exchange and power in social life. Wiley.

Bregenzer, A., Felfe, J., Bergner, S., \& Jiménez, P. (2019). How followers' emotional stability and cultural value orientations moderate the impact of health-promoting leadership and abusive supervision on health-related resources. German Journal of Human Resource Management: Zeitschrift Für Personalforschung, 33(4), 307-336. https://doi.org/10.1177/2397002218823300

Chen, X., \& Shen, W. (2014). Empirical Approaches to Organization and Management Research (3rd ed.). Peking University Publishing Company.

Cooper, C., \& Lu, L. (2016). Presenteeism as a global phenomenon-Unraveling the psychosocial mechanisms from the perspective of social cognitive theory. Cross Cultural \& Strategic Management, 23(2), 216-231. https://doi.org/10.1108/ ccsm-09-2015-0106

Crisp, N., Brownie, S., \& Refsum, C. (2018). Nursing and midwifery: the key to the rapid and cost effective expansion of high-quality universal health. https://ecommons.aku.edu/eastafrica_fhs_ sonam/232. Accessed 4 Dec 2021.

Deery, S., Walsh, J., \& Zatzick, C. D. (2014). A moderated mediation analysis of job demands, presenteeism, and absenteeism. Journal of Occupational and Organizational Psychology, 87(2), 352-369. https://doi.org/10.1111/joop.12051

Demerouti, E., Bakker, A. B., Nachreiner, F., \& Schaufeli, W. B. (2001). The job demands-resources model of burnout. Journal of Applied Psychology, 86(3), 499-512. https://doi.org/10.1037// 0021-9010.86.3.499

Demerouti, E., Le Blanc, P. M., Bakker, A. B., Schaufeli, W. B., \& Hox, J. (2009). Present but sick: A three-wave study on job demands, presenteeism and burnout. Career Development International, 14(1), 50-68. https://doi.org/10.1108/13620430910933574

Derue, D. S., Nahrgang, J. D., Wellman, N., \& Humphrey, S. E. (2011). Trait and behavioral theories of leadership: An integration and meta-analytic test of their relative validity. Personnel Psychology, 64(1), 7-52. https://doi.org/10.1111/j.1744-6570.2010.01201.x

Dietz, C., Zacher, H., Scheel, T., Otto, K., \& Rigotti, T. (2020). Leaders as role models: Effects of leader presenteeism on employee presenteeism and sick leave. Work and Stress, 34(3), 300-322. https://doi.org/10.1080/02678373.2020.1728420

Fang, J., Zhang, M., \& Qiu, H. (2010). Multilevel mediation based on hierarchical linear model. Advances in Psychological Science, 18(8), 1329-1338.

Ferreira, A. I., \& Martinez, L. F. (2012). Presenteeism and burnout among teachers in public and private Portuguese elementary schools. International Journal of Human Resource Management, 23(20), 4380-4390. https://doi.org/10.1080/09585192.2012. 667435

Fiorini, L. A., Houdmont, J., \& Griffiths, A. (2020). Nurses' illness perceptions during presenteeism and absenteeism. Occupational Medicine, 70(2), 101-106. https://doi.org/10.1093/occmed/kqaa0 12

Franke, F., Felfe, J., \& Pundt, A. (2014). The impact of health-oriented leadership on follower health: Development and test of a new instrument measuring health-promoting leadership. German Journal of Human Resource Management, 28(1-2), 139-161. https:// doi.org/10.1177/239700221402800108

Freeling, M., Rainbow, J. G., \& Chamberlain, D. (2020). Painting a picture of nurse presenteeism: A multi-country integrative review. International Journal of Nursing Studies, 109, 103659. https://doi. org/10.1016/j.ijnurstu.2020.103659

Furuichi, W., Shimura, A., Miyama, H., Seki, T., Ono, K., Masuya, J., \& Inoue, T. (2020). Effects of job stressors, stress response, and sleep disturbance on presenteeism in office workers.
Neuropsychiatric Disease and Treatment, 16, 1827-1833. https:// doi.org/10.2147/ndt.s258508

Gilboa, S., Shirom, A., Fried, Y., \& Cooper, C. (2008). A meta-analysis of work demand stressors and job performance: Examining main and moderating effects. Personnel Psychology, 61(2), 227-271. https://doi.org/10.1111/j.1744-6570.2008.00113.x

Gillet, N., Huyghebaert-Zouaghi, T., Reveillere, C., Colombat, P., \& Fouquereau, E. (2020). The effects of job demands on nurses' burnout and presenteeism through sleep quality and relaxation. Journal of Clinical Nursing, 29(3-4), 583-592. https://doi.org/ 10.1111/jocn.15116

Gregersen, S., Vincent-Höper, S., \& Nienhaus, A. (2014). Health-relevant leadership behaviour: A comparison of leadership constructs. German Journal of Human Resource Management, 28(1-2), 117138. https://doi.org/10.1177/239700221402800107

Gustafsson, K., Marklund, S., Leineweber, C., Bergström, G., Aboagye, E., \& Helgesson, M. (2020). Presenteeism, psychosocial working conditions and work ability among care workers-A cross-sectional Swedish population-based study. International Journal of Environmental Research and Public Health, 17(7), 2419. https://doi. org/10.3390/ijerph17072419

Hewison, A., \& Griffiths, M. (2004). Leadership development in health care: A word of caution. Journal of Health Organization and Management, 18(6), 464-473. https://doi.org/10.1108/14777 260410570018

Ingwell-Spolan, C. (2016). Perceived work experiences of chief nursing officers. Nurse Leader, 14(2), 134-138. https://doi.org/10.1016/j. $\mathrm{mnl}$.2015.04.001

James, L. R. (1982). Aggregation bias in estimates of perceptual agreement. Journal of Applied Psychology, 67(2), 219. https://doi.org/ 10.1037/0021-9010.67.2.219

Jiménez, P., Winkler, B., \& Bregenzer, A. (2017a). Developing sustainable workplaces with leadership: Feedback about organizational working conditions to support leaders in health-promoting behavior. Sustainability, 9(11), 1944. https://doi.org/10.3390/su9111944

Jiménez, P., Winkler, B., \& Dunkl, A. (2017b). Creating a healthy working environment with leadership: The concept of health-promoting leadership. The International Journal of Human Resource Management, 28(17), 2430-2448. https://doi.org/10.1080/09585 192.2015.1137609

Johns, G. (2010). Presenteeism in the workplace: A review and research agenda. Journal of Organizational Behavior, 31(4), 519-542. https://doi.org/10.1002/job.630

Judge, T. A., \& Kammeyer-Mueller, J. D. (2012). General and specific measures in organizational behavior research: Considerations, examples, and recommendations for researchers. Journal of Organizational Behavior, 33(2), 161-174. https://doi.org/10. 1002/job.764

Karanika-Murray, M., \& Biron, C. (2020). The health-performance framework of presenteeism: Towards understanding an adaptive behaviour. Human Relations, 73(2), 242-261. https://doi.org/10. $1177 / 0018726719827081$

Kelloway, E. K., \& Barling, J. (2010). Leadership development as an intervention in occupational health psychology. Work and Stress, 24(3), 260-279. https://doi.org/10.1080/02678373.2010.518441

Lee, D. W., Lee, J., Kim, H. R., \& Kang, M. Y. (2020). Association of long working hours and health-related productivity loss, and its differential impact by income level: A cross-sectional study of the Korean workers. Journal of Occupational Health, 62, e12190. https://doi.org/10.1002/1348-9585.12190

Letvak, S. A., Ruhm, C. J., \& Gupta, S. N. (2012). Nurses' presenteeism and its effects on self-reported quality of care and costs. American Journal of Nursing, 112(2), 30-38. https://doi.org/10. 1097/01.NAJ.0000411176.15696.f9

Li, Y., Zhang, J., Wang, S., \& Guo, S. (2019). The effect of presenteeism on productivity loss in nurses: The mediation of health and 
the moderation of general self-efficacy. Frontiers in Psychology, 10, 1745. https://doi.org/10.3389/fpsyg.2019.01745

Li, Z., Wang, Z., Zhu, Z., \& Zhan, X. (2018). Performance pressure and unethical pro-organizational behavior: Based on cognitive appraisal theory of emotion. Chinese Journal of Management, 15(3), 358-365. https://doi.org/10.3969/j.issn.1672-884x.2018. 03.006

Liu, B. (2016). Health-promotion leadership: Its definition measurement and effect on employees' health. Human Resources Development of China, 33(115), 48-56. https://doi.org/10.16471/j.cnki. $11-2822 / \mathrm{c} .2016 .15 .005$

Liu, D., Zhang, Z., \& Wang, M. (2012). Moderated mediation and mediated moderation: Theoretical construction and model test. X. Chen, S. Xu \& J. Fan (Eds.). Peking University Publishing Company

Liu, Y. (2008). Management Psychology. Tsinghua University Publishing Company.

Lohaus, D., \& Habermann, W. (2019). Presenteeism: A review and research directions. Human Resource Management Review, 29(1), 43-58. https://doi.org/10.1016/j.hrmr.2018.02.010

Miraglia, M., \& Johns, G. (2016). Going to work ill: A meta-analysis of the correlates of presenteeism and a dual-path model. Journal of Occupational Health Psychology, 21(3), 261-283. https://doi. org/10.1037/ocp0000015

Mitchell, M. S., Baer, M. D., Ambrose, M. L., Folger, R., \& Palmer, N. F. (2018). Cheating under pressure: A self-protection model of workplace cheating behavior. Journal of Applied Psychology, 103(1), 54-73. https://doi.org/10.1037/ap10000254

Muthén, L.K. and Muthén, B.O. (2017). Mplus User's Guide. Eighth Edition. Los Angeles: Muthén \& Muthén.

Navarro, A., Salas-Nicas, S., Moncada, S., Llorens, C., \& MolineroRuiz, E. (2018). Prevalence, associated factors and reasons for sickness presenteeism: A cross-sectional nationally representative study of salaried workers in Spain, 2016. British Medical Journal Open, 8(7), e021212. https://doi.org/10.1136/bmjop en-2017-021212

Peterson, M., Smith, P., Akande, A., Ayestarán, S., Bochner, S., Callan, V., Cho, N., Jesuino, J., D’Amorim, M., Francois, P.-H., Hofmann, K., Koopman, P., Leung, K., Lim, T., Mortazavi, S., Munene, J., Raford, M., Ropo, A., Savage, G., \& Viedge, C. (1995). Role conflict, ambiguity, and overload: A 21-nation study. The Academy of Management Journal, 38, 429-452. https://doi.org/10.2307/ 256687

Rainbow, J. G., Drake, D. A., \& Steege, L. M. (2020). Nurse health, work environment, presenteeism and patient safety. Western Journal of Nursing Research, 42(5), 332-339. https://doi.org/10.1177/ 0193945919863409

Ruhle, S. A., Breitsohl, H., Aboagye, E., Baba, V., Biron, C., Correia Leal, C., Dietz, C., Ferreira, A. I., Gerich, J., Johns, G., KaranikaMurray, M., Lohaus, D., Løkke, A., Lopes, S. L., Martinez, L. F., Miraglia, M., Muschalla, B., Poethke, U., Sarwat, N., ... Yang, T. (2019). "To work, or not to work, that is the question" - Recent trends and avenues for research on presenteeism. European Journal of Work and Organizational Psychology, 29(3), 344-363. https://doi.org/10.1080/1359432x.2019.1704734

Shan, G., Wang, S., Feng, K., Wang, W., Guo, S., \& Li, Y. (2021a). Development and validity of the nurse presenteeism questionnaire. Frontiers in Psychology, 12, 679801. https://doi.org/10. 3389/fpsyg.2021.679801

Shan, G., Wang, S., Wang, W., Guo, S., \& Li, Y. (2021b). Presenteeism in nurses: Prevalence, consequences, and causes from the perspectives of nurses and chief nurses. Frontiers in Psychiatry, 11, 584040. https://doi.org/10.3389/fpsyt.2020.584040
Shimizu, H. (2016). An introduction to the statistical free software HAD: Suggestions to improve teaching, learning and practice data analysis. Journal of Media, Information and Communication, 1, 59-73.

Skarholt, K., Blix, E. H., Sandsund, M., \& Andersen, T. K. (2016). Health promoting leadership practices in four Norwegian industries. Health Promotion International, 31(4), 936-945. https://doi. org/10.1093/heapro/dav077

Sun, J., \& Zhang, Y. (2015). Presenteeism in the workplace: A new topic in organization and management research. Advances in Psychological Science., 23(4), 654-668. https://doi.org/10.3724/SP.J. 1042.2015.00654

Turgut, S., Schlachter, S., Michel, A., \& Sonntag, K. (2020). Antecedents of health-promoting leadership and workload as moderator. Journal of Leadership \& Organizational Studies, 27(2), 203-214. https://doi.org/10.1177/1548051819848988

Veltman, J. A., \& Gaillard, A. W. K. (1996). Physiological indices of workload in a simulated flight task. Biological Psychology, 42(3), 323-342. https://doi.org/10.1016/0301-0511(95)05165-1

Wang, M., \& Li, S. (2017). The influence of workload on perceived intragroup conflicts-the moderating effects of locus of control and affect-based trust. Management Review, 29(4), 122-133. https://doi.org/10.14120/j.cnki.cn11-5057/f.2017.04.012

Wang, Y., Chen, C.-C., Lu, L., Eisenberger, R., \& Fosh, P. (2018). Effects of leader-member exchange and workload on presenteeism. Journal of Managerial Psychology, 33(7-8), 511-523. https://doi.org/10.1108/jmp-11-2017-0414

Wang, Z., Xu, H., \& Du, C. (2015). The trickle-down effect in leadership research: A review and prospect. Advances in Psychological Science, 23(6), 1079-1094. https://doi.org/10.3724/SP.J.1042. 2015.01079

Wegge, J., Shemla, M., \& Haslam, S. A. (2014). Leader behavior as a determinant of health at work: Specification and evidence of five key pathways. Zeitschrift Fur Personalforschung, 28(1-2), 6-23. https://doi.org/10.1688/ZfP-2014-01-Wegge

Yao, L., Li, P., \& Wildy, H. (2021). Health-promoting leadership: Concept, measurement, and research framework. Frontiers in Psychology, 12, 602333. https://doi.org/10.3389/fpsyg.2021.602333

Zhang, J., Guo, S., \& Li, Y. (2018). Mediating effect of presenteeism on relationships among work family conflict and psychological symptom, job satisfaction in nurses. Chinese Mental Health Journal, 32(6), 515-520. https://doi.org/10.3969/j.issn.1000-6729.2018. 06.012

Zhang, J., Wang, S., Wang, W., Guo, S., \& Li, Y. (2019). Effect of presenteeism on work engagement in nurses: role of emotional exhaustion and distributive justice. Chinese Journal of Clinical Psychology, 27(4), 808-811. https://doi.org/10.16128/j.cnki.10053611.2019.04.035

Zhang, L., Xue, X., \& Zhao, J. (2019). Discrimination perception, depression, and academic achievement in rural left-behind children: A longitudinal mediation model. Journal of Psychological Science, 42(3), 584-590. https://doi.org/10.16719/j.cnki.16716981.20190311

Zhou, M., Lin, Z., Luo, D., Gu, F., \& Gu, Z. (2021). Research status and hot spots of male nurses in China in recent 10 years based on bibliometrics. Chinese Journal of Modern Nursing, 27(3), 334 339. https://doi.org/10.3760/cma.j.cn115682-20200526-03582

Publisher's Note Springer Nature remains neutral with regard to jurisdictional claims in published maps and institutional affiliations. 